\title{
El Derecho constitucional, el nuevo indio y el Estado: nueva agenda para la investigación
}

\author{
Constitutional Law, the new indigenous subject and the State: a new research \\ agenda
}

\author{
Pável H. VAler Bellota ${ }^{1}$ \\ Universidad Nacional de San Antonio Abad del Cusco, Perú
}

\begin{abstract}
RESUMEN El descubrimiento del indígena fue el mayor hallazgo de las Ciencias Sociales peruanas del siglo xx. Para el campo jurídico, sin embargo, este descubrimiento es reciente y, se podría decir casi ausente. La Antropología jurídica y de los modelos políticos pueden y deben revertir la ausencia del hecho y del sujeto indígena en las ciencias del Estado, del poder, del Derecho Constitucional. Por ello, es necesario diseñar una nueva agenda de investigación que junte aportes de estas disciplinas. Se debe explicar - desde un punto de vista interdisciplinario jurídico, sociológico, antropológico cultural, y tomando en cuenta los aportes de la ciencia política- las causas y consecuencias del Derecho Constitucional.
\end{abstract}

En este artículo se bosqueja dicha agenda para dar respuesta a la pregunta metodológica general de ¿cómo ha sido y es el Derecho Constitucional respecto a la diferencia cultural de los ciudadanos? y, de manera específica intenta responder a interrogantes como: ¿cuáles han sido las bases culturales e ideológicas que han fundamentado su elaboración y desarrollo? ¿a favor de qué grupo cultural se ha construido el Derecho Político? Asimismo, se plantean las respuestas, a manera de hipótesis, para describir el discurso del Derecho Constitucional peruano respecto a la multiculturalidad de su sociedad.

1. Profesor de Facultad de Derecho y Ciencias Políticas de la Universidad Nacional de San Antonio Abad del Cusco. Doctor por la Universidad del País Vasco (Departamento de Derecho Constitucional, Administrativo y Filosofía del Derecho). Ha obtenido el Diploma de Estudios Avanzados en Filosofía del Derecho en la Universidad de Zaragoza. Correo electrónico: pvalerb@ yahoo.com. 
PALABRAS CLAVE Derecho constitucional, multiculturalismo, pueblos indígenas, poscolonialismo, Perú.

ABSTRACT The discovery of the indigenous citizen was the major finding of the social sciences in Peru in the twentieth century. In the field of legal research, however, this discovery is new and, it might be said, almost absent. The anthropology of legal and political models can and should reverse this absence of the indigenous subject, and indigenous social reality, from the sciences of the State, political power and constitutional law.

It is therefore necessary to design a new research agenda to gather contributions from these disciplines. The causes and consequences of constitutional law in Peru must be explained from an interdisciplinary legal, sociological, anthropological, cultural standpoint, taking into account the contributions of political science.

This article outlines that agenda in order to answer a general methodological question: How has Peruvian Constitutional law dealt with the cultural differences of its citizens in the past, and how does it do so in the present? It also attempts to answer specific questions like: What has been the cultural and ideological basis that has supported its development? In favor of which cultural group has political law been constructed in this country? And finally it provides hypothetical answers describing the discourse of Peruvian Constitutional law regarding multicultural society.

KEYWORDS Constitutional law, Multiculturalism, Indigenous Peoples, Postcolonialism, Peru.

\section{El Derecho político, el yachaq² Arguedas y los juristas}

El descubrimiento del indígena fue el mayor hallazgo de las Ciencias Sociales peruanas del siglo xx. Este descubrimiento significó una ruptura con la ideología conservadora de los todopoderosos doctores, adueñados de las instituciones hegemónicas de producción de conocimiento, que construían la realidad peruana con un imaginario monocolor: una sociedad de una sola cultura, la criolla-hispana.

La ruptura ideológica en el imaginario social hegemónico tiene en José María Arguedas, el sobresaliente intelectual quechua, un exponente antropológico y literario de la necesidad -el deber- de orientar el enfoque, la inspiración y la proyección de las Ciencias Sociales hacia los temas específicos de la multiculturalidad -y el indiorecién descubiertos:

2. "Yachaq. adj. y s. Persona que sabe; sabedor, conocedor, instruido; educado, ilustrado, amaestrado, adiestrado". ACADEMIA MAYOR DE LA LENGUA QUECHUA (2005). 
“Nuestro plan es oponer la producción nuestra a las del otro bando. ¿Cuál es la literatura verdaderamente representativa del Perú? ¿Cuál es la que vale? Demostraremos que la nuestra; frente a esa producción endeble, mediocrísima y artificiosa de ellos; mostraremos la nuestra; plena de vida, llena de juventud y de un valor artístico y humano indiscutible. Ese es nuestro plan"3.

En la investigación jurídica, sin embargo, la valoración del enfoque "nuestro", la apreciación del estudio de la realidad social cultural peruana heterogénea, compuesta por varias naciones y grupos étnicos, es nueva y se podría decir casi ausente. Esta ausencia de la multiculturalidad en la investigación jurídica está emparentada con la idea de que es normal desconocer, negar, la existencia histórica de todo un pueblo, y ningunear su cultura.

Contrario a dicho desconocimiento, para José María Arguedas, el papel de los intelectuales en la formación de un nuevo saber, de una nueva conciencia nacional reintegrada con el hecho indígena, es fundamental. Su obra esta orientada a exigir a los doctores que sean fieles al pueblo:

"que beban en el pozo de sus tradiciones míticas, comunitarias y no competitivas, asimilando las grandes ideas y técnicas de la cultura occidental; sólo así serán creativos y no sólo sus imitadores" 4 .

Este llamado a la autenticidad infunde a decir que en el campo del Derecho Público es necesario describir y explicar -desde un punto de vista sociológico, cultural, y tomando en cuenta los aportes de la Ciencia Política- las causas y consecuencias del Derecho Constitucional. Es imperioso dar respuesta a la pregunta general de: ¿cómo ha sido y es el Derecho Constitucional respecto a la diferencia cultural de los ciudadanos?; y, en específico, se debe responder a interrogantes como: ¿cuáles han sido las bases culturales e ideológicas que han fundamentado su elaboración y desarrollo? ¿A favor de qué grupo cultural se ha construido el Derecho Político?

Estas preguntas son novedosas en las investigaciones sobre el Derecho Constitucional; son cuestiones que parecen provenir más de la Antropología que de una inspiración jurídica, que, por lo general, se ha centrado única y casi en exclusiva en el estudio de la norma positiva (la ley escrita). Y, aun dentro de la Antropología, en el Perú, estas preguntas son nuevas, ya que el estudio desde esta ciencia del fenómeno jurídico y político -específicamente de la investigación del campo del Derecho y su

3. Cfr. QUINTANILLA PONCE (2000).

4. Ibid. "En sociedades de escasez y débil desarrollo del capitalismo como la peruana, la condición del intelectual es muy precaria por extraña; porque pareciera no encajar con las necesidades de su funcionamiento. Porque lo fundamental en ella resulta la lucha contra la naturaleza, la producción de los bienes y servicios que sus gentes necesitan. Un letrado sólo se concibe como funcionario al servicio del poder, o de la enseñanza de las técnicas que los trabajadores necesitan para ser más productivos". 
relación con los órdenes de la cultura- es una tarea aún pendiente. La ausencia de dichos temas en el Derecho y las Ciencias Sociales representan un vacío intelectual en vista a la enorme multiculturalidad de nuestras sociedades.

De manera tradicional, el hecho multicultural ha sido negado, escondido, invisibilizado, olvidado. Fue convertido por los grupos sociales hegemónicos en muestra de 'atraso', de vergüenza atávica, en fuente de una 'utopía arcaica's que había que desaparecer si se quería alcanzar el añorado 'desarrollo' social y cultural. Ese ha sido el discurso del poder, la fuente de su legitimidad, la herramienta justificativa de su Derecho. Muchas han sido las voces que se han levantado -desde las Ciencias Socialescontra esa legitimidad negadora del otro, estas han provenido de la Antropología, de la Historia, de la Sociología; pero de manera aún tímida empiezan a asomarse a los estudios del Derecho.

Esas voces críticas han sido fundadas por disciplinas diferentes a los estudios del campo jurídico. En un conocido discurso, al recibir uno de los galardones con los que fue premiado a lo largo de su vida por su obra antropológica y literaria, José María Arguedas, dijo: “(...) yo no soy un aculturado; yo soy un peruano que orgullosamente, como un demonio feliz habla en cristiano y en indio, en español y en quechua (...)". Este autor -a quien se puede describir como el prototipo del nuevo indio quechua ilustrado del siglo $\mathrm{xx}$ - es quien inauguró e inspira hasta el momento (desde la segunda mitad de ese siglo), las investigaciones centradas en el indio, desde el punto de vista del indio.

Se ha dicho que, la realidad multicultural -la existencia del ciudadano indígenafue el gran descubrimiento de las Ciencias Sociales en el anterior siglo. Esta realidad invita a los investigadores del Derecho a hacer nuevos hallazgos relacionados con el reconocimiento jurídico de la diversidad cultural y su traducción en políticas públicas.

Pero no es tarea fácil para quien investiga el Derecho. Muchas dificultades conspiran contra esta empresa. Tal vez la dificultad más ardua de superar es la concepción imperante en la academia respecto a la delimitación arbitraria de la materia del Derecho, es decir, lo que se supone deben de ser los estudios del Derecho. Lo que se enseña en las facultades de la mayor parte del mundo sobre el campo jurídico es solo una pequeña parte de él, su porción positiva y dogmática-jurídica; dejando de lado o restando importancia a la enseñanza y el escudriñamiento íntegro del fenómeno

5. Me refiero a las ideas descritas en el ensayo de VARGAS LLOSA (2015). 
jurídico, desdeñando la investigación empírica y los métodos que puedan dar cuenta de las condiciones sociales completas del Derecho ${ }^{6}$.

Se ha difundido, hasta hacerse hegemónica, la metodología de la jurisprudencia analítica para la cual la investigación jurídica debe centrarse en los conceptos legales contenidos en las normas, en la forma cómo son utilizados dichos conceptos y la manera cómo se piensa acerca del Derecho y del sistema legal7. Otros autores muy difundidos han propuesto que una suerte de limpieza ética del Derecho para lograr que su análisis científico se oriente solo a las normas positivas (propiamente del Estado, del Derecho escrito, de los actos jurídicos interindividuales y de las sentencias) ${ }^{8}$.

Dicha metodología tiene en su base a la teoría jurídica normativa. Roger Cotterell explica que esta entiende que el estudio del Derecho debe centrarse en los conceptos, las reglas y la jurisprudencia emitida por los jueces o la teoría implícita en ellas. Para esta corriente, heredera del formalismo jurídico, la teoría del Derecho debe ocuparse de fijar su significado de forma más general y abstracta, y responder a la preocupación profesional de los abogados por las definiciones. Para la teoría jurídica normativa “(...) especificar lo que es el derecho resulta lo mismo que especificar qué resulta válido como derecho, en qué argumentos se puede confiar ante un tribunal o cómo determinar cuáles serán los resultados legales cuando las reglas sean interpretadas y aplicadas por las cortes o por otras autoridades jurídicas"9.

El resultado práctico de la hegemonía de las corrientes teóricas formalistas sobre la academia es que los juristas solo se fijan en las normas, las reglas y las categorías para su interpretación, sin poder observar la realidad existente más allá de la ley escrita - de la letra negra de la ley- sin atinar a situarse, al menos momentáneamente, fuera del sistema dogmático-jurídico para apreciar el fenómeno social llamado Derecho en su integridad. Esta visión del Derecho con un solo ojo ha originado que casi todos los estudios de la ley desechen de sus enfoques una mirada a la realidad social, excluyan

6. Se atribuye a un jurista italiano, crítico de las escuelas del formalismo y del positivismo jurídico, el criterio de que las crisis sociales y políticas hacen que se devalúe el trabajo de los juristas, en especial las crisis que traen consigo el deterioro de las libertades políticas: "cuando el método de los juristas queda reducido a una casuística fría y estéril, indigna del hombre de ciencia, y el estudio del Derecho a un aprendizaje molesto de las leyes vigentes, la sociedad por lo común o sale de una crisis o está para entrar en ella. El régimen despótico, aunque sea el de un Bonaparte, pide a sus escuelas que le preparen juristas que sean ejecutores, no críticos, que apliquen las leyes, pero no las juzguen". Angelo SRAFFA “La riforme della legislazione commerciale e la funzione dei juristi”, en Revista de Diritto comerciale, Noa 1. 1913. Cfr. ALZAGA VILLAMIL (1997).

7. Esta sería la propuesta metodolígica de H.L.A. Hart. WACKS (2014).

8. Para una presentación resumida de la Teoría del Derecho de Hans Kelsen véase WACKS (2014).

9. COTTERRELL (2010). 
considerar que el Derecho más allá de ser ley escrita es también un fenómeno social, es el producto político de una negociación (o imposición) que busca la construcción y legitimación de una hegemonía determinada ${ }^{10}$. Desde esas metodologías formalistas del Derecho es fácil pasar al desconocimiento de la realidad social multicultural.

Por ello, para evitar seguir incurriendo en metodologías y teorías que no dan cuenta de la realidad, es importante ponderar el sentido empírico del Derecho; hacer un análisis de las causas y los efectos fácticos concretos de la existencia de un único orden jurídico-político en medio de una sociedad multicultural caracterizada por la pluralidad de identidades étnico-nacionales, sus condicionantes (factores históricos, económicos, políticos, ideológicos) y, también, sus efectos sobre esos condicionantes. Se debe tener claro que el Derecho es un mecanismo de hegemonía y un instrumento de control social, que se ha construido y ejercido al margen de un gran segmento de ciudadanos a quienes se les ha negado la participación en la constitución de la sociedad política, debido a su identidad étnico-nacional.

El Derecho puede ser, y debe transformarse, en un mecanismo y un instrumento de liberación, de emancipación social, de construcción de la hegemonía pública. Para esta tarea es necesario transformarlo en un Derecho humilde, un Derecho construido desde abajo y para los de abajo, un Derecho que reconozca al otro culturalmente diferente, en un marco de producción democrática de la norma jurídica, que integre el pluralismo emancipatorio ${ }^{11}$.

Para ello, el Derecho, y las Ciencias Sociales en general, deben dotarse de una nueva y más actual agenda de investigación a tono con el reconocimiento de la diversidad cultural. Dicha agenda nueva se hace aun mucho más necesaria si se toman en cuenta los procesos sociales y políticos - culturales- que se están desarrollando en la historia contemporánea de América Latina. El nuevo indio renace en América Latina.

10. Para una idea general del Derecho como instrumento de hegemonía puede consultarse, entre otros, el trabajo de NOGUERA FERNÁNDEZ (2006).

11. Estas ideas son tomadas prestadas de las propuestas de Antonio Carlos Wolkmer. Una síntesis de su propuesta de pluralismo emancipatorio, tributaria de la teoría sociológica jurídica de Eugen Erlich, puede encontrarse en el trabajo de SÁNCHEZ RUBIO (2008) pp. 111-129. 


\section{La historia contemporánea, el nuevo indio y el Estado}

El nuevo indio se ha levantado en América Latina. Dicha insurgencia es parte del fenómeno político contemporáneo llamado regreso a las culturas ${ }^{12}$, que se puede apreciar en la historia contemporánea de varios países de América, que ha planteado nuevos paradigmas políticos y planteamientos económicos alternativos.

El retorno cultural proviene de dos vertientes. La primera es una reivindicación de valores históricos, de cultura étnica y pertenencia nacional a un grupo subordinado diferente del grupo criollo occidental preeminente (o criollo hispano). Y la segunda, una respuesta de los nuevos actores sociales y políticos al fracaso de las promesas de emancipación de la civilización capitalista occidental planteado en su programa Ilustrado. Ambas pueden ser apreciadas como un solo fenómeno social identitario y reivindicativo, como un nuevo movimiento social frente a la 'amenaza global'13.

Los nuevos movimientos sociales y políticos contemporáneos, impulsados por una renovada energía que ha surgido desde el interior más íntimo del recuerdo histórico, de cuando el reinar indígena se trocó en vasallaje ${ }^{14}$, recobran las identidades precolombinas, abren la tendencia de aprovechar las formas culturales más elevadas de la historia de América y se expresan en el resurgimiento de los movimientos de los pueblos indígenas que, desde los años ochenta del siglo xx, han sacudido el continente. Este movimiento social puede rastrearse en la historia hasta la resistencia nacional de los vencidos en las contiendas de la conquista de América. Francisco Letamendía propone su lectura como un verdadero movimiento nacional periférico ${ }^{15}$, cuyos protagonistas no son ya los Estados y sus políticas populistas (como las políticas indigenistas que fueron desplegadas con cierto éxito hasta mediados de 1970), sino son los indígenas mismos. Se trata de un nuevo indigenismo que puede ser denominado indianismo ${ }^{16}$.

12. El "regreso o retorno de las culturas" es una expresión adecuada para representar el resurgimiento en la arena política y social de los movimientos indígenas de América Latina, y las llamadas minorías nacionales en Europa. Esta expresión es una propuesta de CABALLERO HARRIET (2000) pp. 13-43.

13. Para más detalle sobre el "regreso a las culturas" en Latinoamérica véase VALER BELLOTA (2008).

14. Esta expresión es tomada de Garcilaso de la Vega (El Inca) en su obra Los comentarios reales de los incas: "De las grandezas y prosperidades pasadas venían a las cosas presentes, lloraban sus reyes muertos, enejanado su imperio y acabada su república, etc. Estas y otras semejantes pláticas tenían los incas y pallas en sus visitas, y con la memoria del bien perdido siempre acababan su conversación en lágrimas y llanto, diciendo "Trocósenos el reinar en vasallaje”.

15. LETAMENDÍA (1997).

16. LETAMENDÍA (2016) pp. 43-63. 


\subsection{El nuevo indio, ciudadanía y emancipación}

En el Cusco, ciudad 'ombligo' de la América indígena, en la primera mitad de siglo xx, Uriel García pronosticó que las identidades culturales genuinas se fundirían, sin perder su esencia autóctona, con los mejores aportes de la América contemporánea. Y ese pronóstico parece estarse cumpliendo. Ahora, podemos decir, que el ciudadano se convierte en el nuevo indio ${ }^{17}$. Es en la ciudadanía plena, en la afirmación de la igualdad de derechos sin distingos para todos los ciudadanos, en el reconocimiento de la diferencia cultural del origen étnico nacional del indígena, y en la nueva distribución descentralista del poder político, que se realiza el ideal de la emancipación de los pueblos originarios del continente.

El indígena se transforma en nuevo indio mediante la acción y la participación políticas. Cuando el segmento autóctono de nuestras sociedades toma conciencia de su potencial político, fortalecido por las nuevas narrativas descolonizadoras y emancipadoras americanas, desarrolla su acción política y comienza su camino a la superación de su condición de subordinado. En el engarzamiento del indígena en los procesos de descolonización y emancipación americanos, surge el nuevo indio.

Qué significa redimir al indio, es decir, qué significado y contenido debe tener la liberación del indio de su obligación de ser el sostén económico del Perú y de otros Estados americanos. Cómo librarlo de ser quien aporta la mano de obra que cincela el progreso de las ciudades a cambio de su alma cultural, de su condición de subalterno frente a los señores, de ser el segmento social que pone los muertos en las guerras de la historia y en las protestas sociales de hoy. Qué significa liberarle de su dolor, de su situación penosa de ser el aculturado, el "cholo", el que está condenado a aprender con la verdadera educación la correcta palabra, el que asimila la cultura "delicada" de los vencedores y abandona la suya propia.

Uriel García, en su famosa obra El nuevo indio (1930) plantea que, en buena cuenta, esta liberación consiste en elevar al indio a la altura de la conciencia americana del presente. Fortalecer la simplicidad de su alma, desde la grandeza de su tradición y su cultura, acrecentándola, con la riqueza espiritual de hoy. El indígena debe dotarse de una nueva conciencia americana, fortalecer su tradición fecunda para hacerla más grande y renovarla, sin permanecer únicamente en el pasado ${ }^{18}$.

17. GARCÍA (1930 - reimpresión 1973).

18. Uriel García plantea una ruptura con la tradición del indio antiguo, una renovación profunda de su ser material e intelectual. Propone la superación del "agrarismo" y la apertura de su actividad hacia todos los campos económicos, sociales y políticos contemporáneos. 
Esta obra (El nuevo indio) es en especial valiosa cuando plantea que el indígena tiene aptitud para su propia redención, y que esta consiste en un proceso personal, interno, individual y también un proceso colectivo. En este paso encarnará las ideas nuevas americanas y resurgirá por su propio impulso. En palabras de Uriel García: "Cuando el indio sea realmente nuevo indio tendrá aptitud redentora, es decir, cuando sea un hombre distinto al que es. Y solo entonces producirá sus guías verdaderos y el 'problema del indio' será, así para la masa como para las generaciones jóvenes urgidas de solucionarlo, un estado de rebelión o no será nada” (p. 119).

Continúa este autor, manifestando que la cultura de América que liquide los rezagos tradicionales y haga avanzar el espíritu neoindiano será fruto de una rebelión interior como de una rebelión contra las fuerzas externas que mantienen el pasado. Se debe resolver no solo el problema para el indio sino de encontrar solución para todo el nuevo indio: "Crear nuevos indios totales".

La redención del indio no es solo la lucha contra el gamonalismo sino, también, contra el centralismo, luchar contra el caciquismo constitucional del centralismo es imprescindible para lograr la emancipación indígena. El regionalismo -descentralismo- es voluntad indiana de creación nacional, es la lucha del campesino serrano contra la urbe europeizante. El regionalismo es una fuerza defensiva de la historia peruana: "Los impulsos de cada zona histórica deben ser incrementados y ser dotados de autonomía. La aldea, la provincia y la ciudad cada cual que cumpla su papel, como así lo mandan los Andes formidables"19.

Esta percepción es acertada, y se expresa a partir de las dos últimas décadas del siglo xx en el indigenismo que ha tomado la forma de un movimiento social sustentado en una especie de nacionalismo contrahegemónico -contestatario y crítico del modelo económico y político- propio de ciertas sociedades (étnicas) subestatales. El indigenismo ha recobrado una de sus formas originales principales de ideología vertebradora de la acción política de colectivos que se proclaman indígenas, autóctonos y superadores de la condición colonial del indio. Estos grupos contrahegemónicos se convierten en actores públicos que devuelven y contestan la construcción nacional de las estructuras y modelos tradicionales de los Estados, y desarrollan, a su vez, su propio discurso nacional. El resurgimiento de los pueblos indígenas, como importantes actores políticos, ha impulsado el surgimiento crítico de herramientas teóricas posmodernas que buscan interpretar el indigenismo de manera más, ya no solo como un fenómeno artístico o estético, sino como un hecho político que transforma el escenario tradicional del Estado ${ }^{20}$.

19. GARCÍA (1930 - reimpresión 1973) p.121.

20. VALER BELLOTA (2011). 
Las ideas de Uriel García encajan con las percepciones del indianismo contemporáneo como movimiento poscolonial. Son percepciones muy adelantadas para su tiempo y, además, acertadas porque se ha hecho patente que, a partir de las dos últimas décadas del siglo $\mathrm{xx}$, el indigenismo ha tomado la forma de un movimiento social que se sustenta en una especie de nacionalismo contrahegemónico -contestatario y crítico del modelo económico y político- propio de ciertas sociedades (étnicas) subestatales.

Los Estados democráticos deben responder de forma apropiada a las demandas sociales del proceso social de regreso de las culturas, de la creación de nuevos indios totales, de una nueva ciudadanía neoindiana. Como parte de esa respuesta deben acomodar y reformar sus instituciones, su modelo político, de manera que dé respuestas democráticas a los procesos culturales contemporáneos. Los procesos sociales de organización indígena; la igualdad, la diversidad, la ciudadanía multicultural ${ }^{21} \mathrm{y}$, en general, las reivindicaciones de la cultura ${ }^{22}$; así como la asunción de nuevos paradigmas políticos y jurídicos que proponen modelos constitucionales emancipatorios democráticos, plantean un nuevo escenario para el constitucionalismo y para todo el Derecho Público en general.

\subsection{El malestar de la cultura en la historia contemporánea}

Desde la apreciación de la historia reciente y de los últimos hechos políticos podemos decir que no se están procesando los requerimientos de esa contemporánea realidad social y política -en especial de las exigencias de los nuevos movimientos sociales de base étnica- en los términos que aconseja la teoría de la democracia como saludables. Podemos afirmar que la multiculturalidad de la sociedad le está explotando en las manos al Estado.

El panorama del malestar de la cultura y sus reivindicaciones han resurgido en la escena peruana reciente de manera abrupta, una muestra de ello ha sido la respuesta del Estado a la protesta indígena que derivó de manera violenta y luctuosa en los hechos de Bagua ${ }^{23}$. Los pueblos indígenas de la Amazonía han mostrado -como la

\section{KYMLICKA (1996).}

\section{BENHABIB (2002).}

23. El 5 de junio de 2009, ante la protesta pacífica de los indígenas amazónicos peruanos que exigían la derogación de una serie de leyes promulgadas, el gobierno peruano decidió reprimir al movimiento con un resultado trágico. La Defensoría del Pueblo informó de: 33 personas fallecidas (23 efectivos policiales, cinco pobladores y cinco indígenas); 83 personas detenidas; 200 personas heridas que recibieron atención médica de hospitales del Ministerio de Salud y de Essalud; y 1,244 indígenas que retornaron a sus comunidades nativas, luego de haber sido empadronados por el Ministerio Público. Véase DEFENSORÍA DEL PUEBLO (2009). 
punta de un iceberg- esta realidad y han materializado medidas de reproche que han mostrado la fuerza de su proceso de organización, contra medidas económicas implementadas por el Estado. Su levantamiento ha dirigido sus demandas contra el sistema legal imperante, han exigido al Estado la derogatoria de leyes que colisionan con la Constitución Política y con el Convenio 169 de la OIT ${ }^{24}$; también que se produzcan cambios constitucionales que reconozcan la diversidad étnico/nacional (cultural) del país y se legisle sobre ella a tono con los convenios internacionales sobre derechos indígenas.

Todo parece indicar que muchos de los conflictos actuales tienen un importante componente cultural, que muestra el descontento existente respecto a las condiciones poscoloniales de la sociedad, que son percibidas como verdaderas causas histórico-coloniales de opresión. Un tema descuidado en el análisis de la conflictividad es el campo de la cultura. Valdría tomar en cuenta que en los conflictos entre las instituciones de la sociedad preeminente, las empresas y los particulares "mistis" ${ }^{25}$ frente a pueblos indígenas se enfrentan diferentes concepciones respecto al Derecho, sobre al concepto de lo justo, acerca de "lo normal" del manejo de los recursos naturales.

Buena parte de los conflictos socioambientales, en el Perú al menos, implican el choque de conceptos civilizacionales diferentes sobre la buena vida. Antonio Peña Jumpa ${ }^{26}$ propone entender el carácter étnico de las confrontaciones, su naturaleza sería más cultural que ambiental o social, porque en estos casos el sujeto clave del conflicto (las organizaciones de los pueblos originarios), con quienes se enfrenta la empresa y los funcionarios del Estado, tienen otra cultura, una manera diferente de ver o pensar la norma y el Derecho ${ }^{27}$.

Esto debe evaluarse en un contexto sociológico político poscolonial. El sistema político/legal de la mayor parte de Estados de América Latina, desde hace cinco siglos, se desenvuelve de espaldas a la mayoría de sus ciudadanos; la ciudadanía se ha desarrollado de tal manera que está estratificada de acuerdo con la clase social, al grupo étnico-cultural, o al género al que pertenezca determinada persona. Así, se ha llegado a establecer un sistema legal consuetudinario -no oficial- por el que se considera como un 'ciudadano normal' a quien es criollo/hispano/occidental de clase

24. Exigen que se dejen sin efecto las leyes № 29317 Nueva Ley Forestal y de Fauna Silvestre, No 29338 Ley de Recursos Hídricos, y los decretos legislativos 1089, 1064 y 1020; también piden que se promulguen nuevos artículos constitucionales que reconozcan la diversidad étnico/ nacional (cultural) del país a tono con los convenios internacionales que reconocen diversos derechos indígenas. Esta lucha es legítima.

25. Mistis (quechua): Mestizos, extraños, afuerinos (traducción del autor).

26. PEÑA JUMPA (2014) p.133.

27. Op. cit., pp. 129-135. 
media o alta. Todo lo que se desvía de esta 'normalidad' es dejado de lado, marginado, excluido y muchas veces criminalizado.

Los pueblos indígenas han sido, a lo largo de la historia de la república, desplazados de las decisiones políticas y del proceso de promulgación de las leyes más importantes. No se les consultó sobre las decisiones políticas que le afectaron debido a la estructura de la Constitución Política realmente existente, cuya característica es la exclusión del sujeto indígena. Aunque es necesario mencionar que se ha producido el reconocimiento del Derecho a la Consulta Previa que, al menos de manera simbólica, es un hito en el reconocimiento del derecho a la participación indígena en las decisiones sobre políticas públicas.

Estos avances, sin embargo, son vaciados de contenido debido al modelo de desarrollo neoliberal que ha aplicado el Estado. Este ha exigido dar las mayores facilidades para la inversión privada de grandes capitales en la explotación de recursos naturales. Ha impuesto que se promulguen leyes que faciliten la entrega a particulares de estos recursos, sin importar que se encuentren en localidades que son parte de territorios indígenas, y con minúsculas (casi retóricas) exigencias de respeto al ambiente ${ }^{28}$. Una pieza importante en este modelo de explotación petrolera y minera ha sido la suscripción del tratado de libre comercio entre Perú y Estados Unidos (USA) ${ }^{29}$. Dicho tratado (TLC) se ha convertido, desde la economía, en la verdadera Constitución Política del Perú -parafraseando al constitucionalista Gavin Anderson ${ }^{30}-$, que ha ordenado al Estado la promulgación de leyes que faciliten su aplicación.

\footnotetext{
28. La mayor parte de la Amazonía peruana esta lotizada a favor de grandes consorcios y empresas petroleras, incluso algunas zonas declaradas como reservas naturales. Y hay una multitud de conflictos desatados entre las empresas mineras y los pueblos indígenas andinos (comunidades campesinas) que se ven despojados de sus territorios que pasan a poder de empresas que casi no les reportan beneficio alguno.

29. Acuerdo de Promoción Comercial Perú - EE.UU, suscrito el 12 de abril de 2006. Mediante resolución legislativa No 28766 y resolución legislativa No 29054, el Congreso de la República aprobó el Acuerdo de Promoción Comercial Perú - Estados Unidos y su Protocolo de Enmienda. Mediante el decreto supremo $\mathrm{N}^{\circ}$ 030-2006-RE y el decreto supremo $\mathrm{N}^{\circ}$ 040-2007-RE, se ratificaron el Acuerdo de Promoción Comercial Perú - Estados Unidos y su mencionado Protocolo de Enmienda. Decreto supremo No 009-2009-MINCETUR para su puesta en ejecución, publicado el 17 de enero de 2009. El Acuerdo entró en vigencia el 1 de febrero de 2009. Disponible en http:// www.acuerdoscomerciales.gob.pe/index.php?option=com_content\&view=category\&layout=blo g\&id=55\&Itemid=78 [fecha de consulta: diciembre de 2018].
}

30. ANDERSON (2005). 
Los planteamientos emancipatorios del multiculturalismo y los nuevos paradigmas democráticos interculturales son contestados de forma inadecuada desde el Estado, muestra de ello ha sido la tragedia de Bagua, y son los recientes conflictos respecto a la explotación minera ${ }^{31}$. Este no es un hecho casual, sino es expresión de una conducta de continuidad del Estado hacia 'sus' minorías nacionales.

\section{Políticas públicas postcoloniales, centralismo cultural y diferencias étnico- nacionales}

El proceso continuo de la relación del Estado con las minorías nacionales puede apreciarse de manera histórica. La república virreinal dual de indios y de españoles, el Estado de los caudillos militares de buena parte del siglo XIX, la república aristocrática, el Estado pretoriano y neoliberal del siglo xx muestran la línea de continuidad que sigue la actuación del Perú en el ámbito de la acomodación de las diferencias étnico-nacionales: los modelos económicos se han engarzado con los modelos políticos y han impuesto un esquema social de hegemonía poscolonial de un grupo económicocultural sobre toda la diversidad del conjunto peruano.

Esto se ha expresado en algunas correspondencias entre la economía y la práctica política del Estado. A los modelos económicos de 'desarrollo' y de crecimiento de una economía orientada hacia afuera del país, les han correspondido el centralismo político, las dictaduras y la democracia de baja intensidad.

Al modelo de centralismo político, que ha concentrado en Lima y en las capitales de departamento las decisiones políticas más importantes y también el poder simbólico, le ha correspondido un modelo de centralismo cultural. El centralismo cultural se expresa en la concentración del poder de decidir qué concepto de buena vida debe seguir la 'nación' peruana, qué preferencia de cultura puede ser considerada buenacorrecta y qué representaciones culturales son las adecuadas. La concentración del poder cultural se enfoca (se produce) en las capitales -la nacional, las departamentales y los demás pueblos de cabecera- y dentro de ellas en un grupo étnico nacional determinado. Y es dicho centralismo político/cultural el que está en la base de un modelo de colonialismo interno, de un modelo particular de nation building.

El proyecto de construcción nacional que se lleva a cabo en Perú, desde el periodo de la Conquista, es el proyecto criollo-hispano. Este proyecto busca la asimilación de los grupos étnico-nacionales diferentes al modelo occidental 'blanco', persigue convertir a todos los ciudadanos, por la persuasión o por la fuerza, en un solo grupo étnico-nacional calcado de Occidente y de la 'criollidad' de las clases dominantes limeñas y centralistas. Con este fin se persiguen los idiomas autóctonos diferentes al castellano, se prohíbe el Derecho existente en las comunidades campesinas y nativas,

31. Puede verse respecto a los graves conflictos sobre minería en Perú: HERRERA, QUIROZ (2015) pp. 215-236. 
se reprimen mediante la violencia cultural las expresiones religiosas andinas, se busca la desposesión legal de las tierras de las comunidades indígenas y nativas, se frena la descentralización política necesaria, se restringe la posibilidad de la existencia de partidos políticos regionales, etcétera.

En medio de estas políticas públicas, se debe considerar al Derecho como un campo en disputa. Muestra de ello es que en el Perú se ha producido en el siglo xx un paulatino reconocimiento de la multiculturalidad. Este tuvo su hito fundador en la Constitución Política de 1920 que reconoció la existencia legal de las "comunidades de indígenas" declarando imprescriptibles sus tierras. A partir de la década de 1969 dicha descripción legal cambia a partir del decreto ley 17716 (24 de julio) que ordena la Reforma Agraria. Esta disposición declara liquidado el sistema de haciendas y latifundios entregando la propiedad de esas tierras a las personas que trabajaban en ellas, abolió el yanaconaje ${ }^{32}$, uniformó a los trabajadores de las antiguas haciendas bajo el término 'campesinos', sean estos indígenas o no. El uso de las palabras 'indio' e 'indígena' en la documentación pública fue prohibido considerándose denigrante el contenido y el significado de estos conceptos.

Después, el decreto ley 20653, en 1974, reconoce a las comunidades nativas -usando este término- para agrupar a los pueblos indígenas de la Amazonía y para diferenciarlos de las comunidades de campesinos de origen andino.

Desde 1995 nuevos vientos empezaron a correr con la ratificación por Perú del Convenio 169 de la OIT sobre pueblos indigenas y tribales en países independientes. Entrado ya el siglo XXI la legislación empezó a reconocer los derechos y la definición específica de los pueblos indígenas. Por ejemplo, la ley 27811, que establece el régimen de protección de los conocimientos colectivos de los pueblos indígenas vinculados a los recursos biológicos. Igualmente, la ley 28736, para la protección de pueblos indígenas u originarios en situación de aislamiento y en situación de contacto inicial.

Existe, entonces, una línea histórica de reconocimiento paulatino. Ahora, podemos afirmar, que este es un tiempo en el que un nuevo sentido común viene surgiendo en el Derecho, junto a nuevos paradigmas jurídicos. Los nuevos valores -entre otrosson la interculturalidad, el respeto de la diferencia, la tolerancia de la discrepancia, los derechos humanos, su acatamiento irrestricto y la necesidad de su promoción por los Estados.

Con referencia a los pueblos originarios, este nuevo sentido común lo indican la Declaración de los Derechos de los Pueblos Indígenas de las Naciones Unidas y el Convenio 169 de la Organización Internacional del Trabajo.

32. Sistema de trabajo no remunerado. 
Y en el ámbito peruano se expresa en la "Ley de consulta previa a los pueblos indígenas u originarios" ( $\mathrm{N}^{\circ} 29785$, de 7 de septiembre de 2011). Esta ley ordinaria reconoce el derecho de los pueblos indígenas a ser consultados de forma previa sobre las medidas legislativas o administrativas que afecten sus derechos colectivos. Establece que la consulta previa es un deber ineludible del Estado que debe realizarse antes de cualquier medida que pueda perturbar derechos colectivos de los pueblos indígenas. Prevé, incluso, el deber del Estado de consultar planes, programas y proyectos de desarrollo nacional y regional que afecten estos derechos (existencia física, identidad cultural, calidad de vida o desarrollo).

\section{Multiculturalidad, proyectos de construcción nacional y debate constitucional}

El Perú es un país con diversos grupos étnicos y nacionales, es una sociedad multicultural en la que diversos grupos de individuos que tienen culturas diferentes -que ocupan, a su vez, un lugar determinado en las posiciones de poder y dominaciónestán en contacto continuo; y en la que se materializan cambios y adaptaciones en los patrones de la cultura original, en las culturas societales de los grupos más débiles sometidos a procesos de colonización o neocolonización ${ }^{33}$.

Desde sus orígenes, el Estado moderno ha afrontado esta realidad multicultural desde diversas perspectivas. Ha proyectado las concepciones culturales y políticas de asimilacionismo y dominación, propias del segmento social criollo-hispano (occidental) hacia los demás grupos étnico-nacionales autóctonos (pueblos indígenas o minorías culturales). Entre estas perspectivas destaca la del Derecho Constitucional, ideario político plasmado en las dieciocho constituciones (y documentos constitucionales) que han regido durante la historia poscolonial peruana.

A lo largo de la historia constitucional del Perú se pueden apreciar unos modelos políticos que han reforzado la relación jurídica de dominación entre los grupos étnicos nacionales, y que han privilegiado la perspectiva del grupo criollo-hispano predominante en la construcción nacional y la construcción del Estado. Esos modelos han descartado la posibilidad de tolerancia de procesos de construcción nacional alternativos. Bajo el manto de la teoría y el constitucionalismo liberal, el grupo privilegiado ha ejercido el poder político institucional descartando la participación de los grupos étnico-nacionales subordinados Y, expulsándolos del contrato social, les ha privado de las posibilidades de desarrollar un proyecto de construcción nacional propio que se exprese y garantice en las Constituciones Políticas.

\footnotetext{
33. Es decir, es una sociedad multicultural en la que el fenómeno de la interculturalidad (entendida como el contacto, intercambio o dialogo entre culturas) es marcada por el hecho colonial, por la colonialidad del poder y del saber.
} 
En la actualidad, el proyecto de construcción nacional excluyente desplegado por los grupos dominantes está siendo cuestionado. Se identifican en el Perú tres grandes periodos constitucionales consecutivos y superpuestos. El primero de 1780 a 1823 , que abarca el periodo revolucionario desde el levantamiento indígena de Tupac Amaru II hasta la independencia del Perú y la redacción de la primera Constitución Política del Estado. El segundo, que desde 1823 comprende el periodo de construcción de la 'nación peruana' sobre bases políticas concebidas por los grupos criollo-hispanos predominantes. Y, un tercero desde la reconstrucción después de la guerra con Chile, que abarca desde fines del siglo XIX (y principios de 1900) hasta la actualidad, con la peculiaridad actual del cambio constitucional que han experimentado los países andinos en las últimas dos décadas ${ }^{34}$.

En este último periodo, en los últimos veinte años, ha aparecido una nueva valoración de los derechos de construcción nacional que pone el acento en la afirmación de la diferencia cultural de los ciudadanos y en el reconocimiento de la existencia de los grupos étnicos heterogéneos y la pluralidad nacional en los Estados andinos. El proyecto hegemónico de construcción nacional, prevalente desde el periodo de la independencia, ha sido cuestionado desde diversas instituciones nacionales e internacionales.

El proceso de globalización ha favorecido fenómenos como la aparición de nuevos paradigmas en la sociedad política mundial, la difusión de las ideas liberales sobre la democracia y su relación con el reconocimiento oficial de la multiculturalidad. En este contexto, los movimientos étnico-nacionales han resurgido en la escena política internacional, ha crecido el convencimiento en la teoría política sobre la posibilidad -y la necesidad- de la construcción democrática de Estados plurinacionales, que pone en cuestión y desacredita el proyecto de construcción de una única 'nación peruana.'

Actualmente, en el Perú, se procesa un debate sobre una nueva constitución que reemplace al texto constitucional de 1993 nacido del golpe de Estado protagonizado por Alberto Fujimori. Se advierte en este proceso la existencia de dos grandes corrientes en pugna, una por la reforma parcial del texto de 1993 y la segunda por la sustitución de este instrumento legal por una nueva Constitución Política que exprese los anhelos de construcción democrática del Estado.

34. GARCÍA BELAUNDE (1992) pp. 147-162. 


\section{Una nueva agenda multicultural de investigación para el Derecho Constitu- cional}

Las anteriores reflexiones y constataciones invitan a a transformar las metodologías y perspectivas gnoseológicas respecto al Derecho Público. Para contribuir a un cambio constitucional democrático, y a una nueva agenda de investigación para el Derecho Constitucional para dicho cambio, debemos tener en cuenta un método de análisis histórico, que considere la realidad constitucional.

El modelo de sociedad multicultural, que se ha ido estableciendo en la Constitución histórica peruana y en el modelo político que ha diseñado, ha sido marcado por la hegemonía de un conjunto de personas de la sociedad 'oficial', conformada por grupos económicos adueñados del poder político, con una característica étnico-cultural determinada (por una especie de oligarquía cultural). Este grupo -criollo hispanistaha basado su discurso político en el liberalismo en sus diferentes versiones, y las ha adaptado de tal manera que parte importante de esta ideología se ha convertido en una fuente teórica política de legitimación del dominio hacia los sectores culturales no hegemónicos.

Su dominio ha sido ejercido a través de la historia a manera de imperio jurídico sobre los derrotados en las guerras de la conquista/invasión del Tawantinsuyo; después sobre las naciones que han cargado en sus espaldas los pasivos de las guerras de la independencia y la emancipación criolla del Perú; y -a fines del anterior siglo- sobre los grupos nacionales subestatales que más han sufrido la catástrofe de la guerra interna, y ante quienes abre sus fauces la violencia cultural que pretende justificar su expropiación: los pueblos indígenas y las minorías culturales.

Dicho modelo político, importado de las metrópolis imperiales, cuenta como parte de sus esquemas de legitimación, con una ciencia oficial -con un discurso sobre la llamada ciencia del Derecho- de la cual han sido expulsados los temas que pueden interesar a los sectores sociales subordinados. De allí la inexistencia y la escasez de investigaciones y estudios del Derecho que se enfoquen sobre los que no tienen poder, quienes aparecen como invisibles en el discurso de la ciencia hegemónica. Por ello es muy importante, en aras de lograr una emancipación de dichos sectores subalternos, que el estudio del Derecho asuma, también, una orientación similar a las 'sociologías de las emergencias' ${ }^{35}$, que haga emerger, surgir desde el olvido y la invisibilidad, a los temas descartados por los estudios tradicionales y conservadores.

Como una parte del esfuerzo de implementar estudios jurídicos de las emergencias, las denominadas 'ciencias jurídicas' tienen que comprender que tienen ante sí un gran reto: revelar, expresar y descubrir nuevos paradigmas políticos constitucionales, hacer que en la América Andina el proyecto excluyente y racista criollo hispano entre

35. SANTOS (2005). 
por fin en su noche definitiva, que sea recluido en los museos como una antigualla, para dar lugar a proyectos multiculturales democráticos y descentralistas de construcción nacional. Las Ciencias Sociales han fundamentado la teoría de una democracia y una ciudadanía multicultural, es a las Ciencias Jurídicas a las que les falta tomar esta fundamentación multicultural y traducirla en contenidos de dogmática jurídica, en propuestas de cambios teóricos y de la propia legislación.

Es fundamental avanzar hacia un nuevo contrato social multicultural, hacia un neoconstitucionalismo multicultural; y en esta tarea las sociedades de América Latina parecen estar en una condición aventajada, mostrada por el surgimiento en su seno de variadas propuestas paradigmáticas que fundamentan un nuevo tipo de convivencia entre las diversas culturas y sus proyectos civilizatorios, que pueden/ deben fundar un nuevo tipo de sociedad en la que los proyectos políticos estén al servicio de la libertad, en la que los proyectos de emancipación colectiva de las culturas, el renacimiento y la recuperación de las lenguas autóctonas, la producción con respeto a la ecología sostenible, y otros "sueños imposibles" en Occidente, puedan ser la realidad cotidiana $^{36}$.

Como ya fue propuesto en una publicación anterior ${ }^{37}$, el neo-constitucionalismo multicultural puede ser descrito, a grandes rasgos, como un conjunto compuesto por tres elementos: (1) un contenido constitucional normativo nuevo de reconocimiento de la preexistencia de las formaciones sociales y políticas autóctonas, es decir, de las naciones indígenas (2) una teoría del Derecho Público y una doctrina constitucional nueva que recoge las demandas democráticas de los movimientos sociales que surgen debido al malestar de la cultura, los movimientos indígenas (étnico-nacionales), (3) el reconocimiento de nuevos derechos y garantías constitucionales basadas en la pertenencia a una cultura nacional determinada. Además, podemos añadir como contenido el proyecto de una nueva distribución del poder político del Estado que tome en cuenta los mecanismos constitucionales democráticos de manejo de las diferencias culturales.

En síntesis, es posible afirmar que el neo-constitucionalismo multicultural está compuesto por elementos referidos al reconocimiento, a la acomodación democrática y a nuevos derechos sobre la base de la consideración de las diferencias culturales (étnicas) de las sociedades políticas. Esta nueva escuela trata de proporcionar un Derecho Constitucional para las sociedades latinoamericanas cuyos grupos subordinados han estado esgrimiendo reivindicaciones de valores históricos, de cultura étnica y pertenencia nacional a un grupo sometido y diferente del grupo preeminente, de subsistencia de sentimientos nacionales precolombinos. Su contenido normativo son

36. CABALLERO HARRIET (2009) pp. 295-300.

37. VALER BELLOTA (2016) pp. 243-254. 
nuevos derechos y nuevas formas de organización del Estado orientadas a acomodar las diferencias étnico/nacionales entre las sociedades nacionales hegemónicas y los pueblos indígenas.

La percepción de esta realidad, junto al neoconstitucionalismo multicultural, hace necesaria una agenda de investigación, a manera de guía, para empezar a andar hacia el objetivo de escudriñar la realidad jurídica constitucional de las sociedades multiculturales. La investigación de Derecho Público y, en particular, la de Derecho Constitucional deberían de abordar al menos estos puntos:

A. Analizar el Derecho Constitucional, y el texto de las constituciones históricas, para establecer las líneas generales de las relaciones jurídico-políticas que han regido, están vigentes en la realidad e influyen en el sistema legal. Investigar, también, el pensamiento constitucional alternativo sobre la diferencia cultural y la sociedad multicultural (en este punto puede ser útil el estudio del llamado "indigenismo jurídico") ${ }^{38}$. El abordaje del Derecho Constitucional debe hacerse de manera comparativa, recurriendo a la realidad constitucional de otros Estados del área andina, en especial Ecuador y Bolivia, así como en la jurisprudencia de la Corte Interamericana de Derechos Humanos ${ }^{39}$.

B. El estudio de las Constituciones debe superar el minúsculo y clásico enfoque jurídico-positivo propio de la escuela formalista del Derecho. Debe ir más lejos haciendo un análisis multidisciplinar tomando perspectivas de otras ciencias, como la Sociología Jurídica, la Ciencia Política y la Antropología. Tiene que entrecruzar las perspectivas de estas ciencias para hacer un estudio de categorías propias de los derechos humanos (en especial los derechos de los pueblos indígenas), del estudio de la teoría del Estado (en especial de la nación como componente del Estado y del derecho a la autodeterminación), del estudio de los grupos culturales y la necesidad de su preservación como requerimiento ético y de derechos fundamentales, así como patrimonio de la humanidad. Este estudio debe basarse, también, en los estándares internacionales y en experiencias de Estados democráticos de composición plurinacional, desde una perspectiva fundamentalmente constitucional.

38. Para este punto se pueden analizar los escritos sobre historia del indigenismo cusqueño.

39. El sistema interamericano de derechos humanos y su Corte han emitido importantes sentencias garantistas. "Los pronunciamientos de la Comisión y de la Corte sobre los derechos humanos constituyen un factor que influyen -en mayor o menor grado- sobre la jurisprudencia y la cultura legal en los distintos países de la región. Comparada con otras regiones del mundo, América Latina ha encabezado el reconocimiento legal de los derechos indígenas, por lo menos en el plano de los cambios normativos". SIEDER (2011). 
C. Se debe analizar el Derecho Constitucional, las Constituciones relevantes de la era republicana, con especial concentración en el tratamiento que estas han dado al fenómeno multiétnico y multinacional. Servirá en dicho análisis, además, el Derecho Político, en especial la organización del Estado, la división geográfica del poder, los mecanismos constitucionales de manejo de las diferencias culturales, la centralización y la descentralización del Estado, entre otros temas en los que el Derecho se encuentra con la Ciencia Política y la Sociología. Este análisis debe ser comparativo con los países del área andina (Bolivia y Ecuador). Además, el estudio del Derecho Constitucional adoptar una perspectiva histórica de análisis para comprender las trazas centrales que la llamada constitución histórica ha mantenido a lo largo de los siglos, en especial para comprender el proceso de conquista/ invasión colonial como un punto de partida ineludible ${ }^{40}$.

\section{Conclusión: Algunas preguntas e hipótesis}

Es necesario detallar algunas preguntas que deben motivar la investigación sobre el modelo político. A continuación se plantean sus respuestas -a manera de lugares comunes $^{41}$ - en la investigación sobre Derecho y pueblos indígenas. Estas respuestas se plantean a manera de hipótesis que deben ser comprobadas o rechazadas por las investigaciones empíricas sobre el Derecho y la multiculturalidad.

A. ¿Como es y ha sido el Derecho Constitucional respecto a la realidad multiétnica y plurinacional? El Derecho Constitucional ha sido elaborado por un grupo social tradicional ligado al poder del Estado, inspirado en tendencias ideológicas globales en boga en los diferentes ámbitos académicos del extranjero, como el liberalismo decimonónico, por ejemplo, dejando en segundo plano la realidad plurinacional; se ha basado más en el Derecho en los libros que en el contexto social. La Constitución Política realmente existente, marcada por la existencia de diferentes grupos étnico-nacionales en el territorio del Estado, no se ha trasladado a plenitud a los textos constitucionales.

\footnotetext{
40. YRIGOYEN FAJARDO (2011).
}

41. Algunas de estas respuestas pueden ser apreciadas en el trabajo de: Roque MANRÍQUEZ (2017) pp. 103-124. 
B. ¿Cuáles han sido las orientaciones generales de las Constituciones Políticas respeto a la diferenciación étnica en general? La Constitución Política del Estado existente más allá de los textos constitucionales tiene sus bases en la realidad social marcada por la existencia de variados grupos nacionales en el territorio del Estado. El Derecho Constitucional (derecho en los libros) ha variado desde el desconocimiento total de la diferencia étnica cultural hasta el reconocimiento formal de la existencia de la alteridad (de 'comunidades de indígenas' y de 'comunidades campesinas e indígenas,' para el caso peruano). Este reconocimiento reciente es valioso en términos históricos. Y es escaso e insuficiente en términos de los nuevos paradigmas de construcción democrática del Estado, de los avances en la teoría que ha producido el debate sobre el reconocimiento de derechos multiculturales, sobre los derechos de las minorías étnicas nacionales y de los pueblos indígenas.

C. ¿Por qué se han producido esas tendencias constitucionales, qué grupo nacional las ha inspirado, para qué y hacia quien? Esto ha respondido a la necesidad de la creación o construcción de la nación peruana surgida después de la independencia; el grupo criollo hispanista necesitaba proyectar su ideal de construcción nacional para asegurarse el control de los recursos, del aparato del Estado, y ejercer dominio sobre otros grupos étnico-nacionales que pudieran significar un riesgo para el proyecto criollo de construcción nacional. El proyecto preponderante, expresado en las normas constitucionales y en las políticas públicas, tiene un enfoque de dominación y asimilación tendiente a la eliminación de las diferencias culturales autóctonas de las nacionalidades diferentes culturalmente a la élite del grupo criollo hispanista.

D. ¿Cómo es el Derecho Constitucional actual respecto a los estándares internacionales sobre derechos de los pueblos indígenas y los proyectos de construcción nacional? El texto constitucional peruano de 1993 fue promulgado cuatro meses antes a la ratificación formal por parte del Estado peruano del Convenio 169 de la OIT. Por ello no ha incorporado los importantes avances en materia de los derechos de los pueblos indígenas que aporta dicho Convenio. Desde 1920, en que la Constitución reconoció para los pueblos indígenas (bajo el adjetivo de comunidades de indígenas) amplios derechos tales como: la autonomía, la inalienabilidad, la imprescriptibilidad e inembargabilidad de sus tierras, la legislación constitucional ha ido variando muy poco hacia el reconocimiento de mayores derechos (en especial de derechos políticos), y, más bien, estos se han recortado, por ejemplo, las previsiones hacia la protección de las tierras y territorio de las 
comunidades campesinas y nativas en el texto constitucional de 1993. Este esquema político, y tratamiento legal de las diferencias etniconacionales, se repite en varios Estados de América del Sur.

E. ¿Cuáles son las tendencias actuales para el posible cambio constitucional respecto a la sociedad multicultural y plurinacional peruana? Existen dos grandes tendencias generales en el pensamiento constitucional respecto a los pueblos indígenas. Una primera tendencia es conservadora (llamada "criolla" en algunos países) basada en el proyecto de construcción nacional del grupo predominante, vinculado al poder del Estado, que propone una ingeniería legal que elimine todas las diferencias étnicas-culturales de los ciudadanos (asimilacionismo nacional-cultural), y la construcción de mecanismos legales de dominación por parte del grupo preeminente hacia los grupos étnicos y culturales diferentes (mecanismos de dominación).

Una segunda tendencia en el pensamiento constitucional respecto a los pueblos indígenas, desarrollada por intelectuales indigenistas ${ }^{42}$ y cada vez más aceptada en variados ámbitos académicos y tendencias ideológicas, es la basada en la afirmación de la diferencia nacional-cultural, en el reconocimiento de la realidad multicultural peruana; que se fundamenta en la tolerancia de variados proyectos de construcción nacional en el ámbito del territorio del Estado. Esta tendencia es contraria al asimilacionismo y propone técnicas pluralistas de tratamiento de la alteridad cultural.

F. ¿Cómo es el Derecho Constitucional peruano comparado con el sistema constitucional de los países del área andina (Bolivia y Ecuador)? En líneas generales, las hipótesis anteriores deben ser similares en los países del área andina, en especial en lo referente a las relaciones jurídicas entre los grupos étnicos/nacionales presentes en la conformación de sus Estados.

42. Con indigenismo peruano me refiero a una posición ideológica tendiente a la defensa de lo que se consideraba indígena. A diferencia de la idea general que este término ha tenido en el ámbito iberoamericano (especialmente para el caso de México), el indigenismo peruano históricamente no se ha traducido a una política de reconocimiento de la alteridad cultural y su plasmación en legislación indigenista estrictamente hablando. Como detalla Waldemmar Espinoza Soriano: "El indigenismo surgió como respuesta a un Estado incapaz de imaginar una sociedad donde puedan convivir distintas etnias en pie de igualdad (a pesar de que los indios componían por aquellos tiempos el 66\% de la población). (...) el indigenismo representó (...) una lucha abierta contra la tiranía y prepotencia de los gamonales (terratenientes y hacendados) y las abundantes clientelas que giraban alrededor de ellos (...) Lógicamente, entonces el discurso de los indigenistas, cuyo proyecto consistía en revalorar y recuperar los derechos del indio, colocándolos a nivel igual que otros peruanos no fue admitido. Por el contrario, la burguesía los miraba como una asociación peligrosísima”. ESPINOZA SORIANO (1995) p. 70. 
La legislación de Bolivia y Ecuador viene dotando de mayores derechos y garantías formales a los grupos étnicos alejados del poder y del manejo del Estado, a partir de fines del siglo xx. Las constituciones políticas de Ecuador (2008) y de Bolivia (2009) se han erigido en nuevos modelos paradigmáticos de reconocimiento de la realidad multinacional de sus sociedades, de la incorporación de los pueblos indígenas como actores políticos fundamentales, y pueden ser la base de desarrollo constitucional a la que podría recurrir el Perú en un próximo cambio constitucional.

\section{Referencias bibliográficas}

ACADEMIA MAYOR DE LA LENGUA Quechua [QheswA SIMI HAMUT'ANA KURAK SUNTUR] (2005): Diccionario quechua-español (2 ${ }^{\text {a }}$ edición, Cusco, Gobierno Regional del Cusco, Perú).

ALZAGA VILLAMIL, Oscar et al (1997): Derecho político español, según la constitución de 1978 (Madrid, Ed. Centro de Est. Ramón Areces, tomo I).

ANDERSON, Gavin (2005): Constitutional Rights after Globalization (Oxford \& Portland, Hart).

BENHABIB, Seyla (2002): The claims of culture. Equality and diversity in the global era (New Jersey, Princenton University Press).

CABALLERO HARRIET, Francisco Javier (200o): “Globalización, Estado y Derecho”. En Anuario de Filosofía del Derecho, Sociedad Española de Filosofía Jurídica y Política, tomo XVII, pp. 13-43.

CABALLERO HARRIET, Francisco Javier (2009): Algunas claves para otra mundialización. Sto. Domingo, Fundación Global Democracia y Desarrollo, pp. 295-30o.

COTTERRELL, Roger (2010): "El concepto sociológico de derecho". En Revista de la Facultad de Derecho, Universidad Nacional de Córdoba, vol. 1, No 1, pp. 51-62. DEFENSORIA DEL PUEBLO. (2009): Actuaciones Humanitarias realizadas por la Defensoría del Pueblo con ocasión de los hechos ocurridos el 5 de junio de 2oo9, en las provincias de Utcubamba y Bagua, Región Amazonas, en el contexto del paro amazónico. Informe de Adjuntía No o062009-DP/ADHPD. Lima. Disponible en www.defensoria.gob.pe/wp-content/uploads/2018/o5/informe-adjuntia006-2009-DP-DHPD.pdf [fecha de consulta: diciembre de 2018].

ESPINOZA SORIANO, Waldemar (1995): "Luis E. Valcárcel, el indigenista e inkanista”.En Ciencias Sociales, UNMSM, IIHS, año 1, No I, pp. 69-82.

GARCÍA BELAUNDE, Domingo (1992): "Los inicios el constitucionalismo peruano (1821-1842)”. En SOBERANES De FERNÁNDEZ, José Luis (ed.): El primer constitucionalismo americano (Madrid, Marcial Pons).

GARCÍA O., José Uriel (1930 - reimpresión 1973): El nuevo indio (Lima, Ed. Universo). 
HERRERA, Honorio Pinto; QUIROZ, Antonio Luyo (2015): "Las Bambas: conflicto social”. En Investigaciones Sociales, UNMSM. vol. 21, No 39, pp. 215-236.

KYMLICKA, Will (1996): Ciudadanía multicultural, (Barcelona, Paidós). LETAMENDÍA, Francisco (1997): Juego de espejos. Conflictos nacionales centroperiferia. (Madrid, Trotta).

LETAMENDÍA, Francisco (2016): "Las identidades del mundo sin centro (1968 hasta hoy)". En Revista de la Facultad de Derecho y Ciencias Políticas UNSAAC. № 9: Derecho y Política en Sociedades Multiculturales, pp. 43-63.

MURRA, John V., López BARALT, Mercedes (1998): Las cartas de Arguedas (2 ${ }^{\mathrm{a}}$ edición, Lima, PUC, Fondo Edit.).

NOGUERA FERNÁNDEZ, Albert (2006): “Durkheim y Weber: surgimiento de la sociología jurídica y teorización del Derecho como instrumento de control social”. En Investigaciones Sociales, UNMSM, año x, N ${ }^{\circ}$ 17, pp. 395-411.

PEÑA JUMPA, Antonio. (2014). "Los conflictos socio-ambientales o socio-culturales en el Perú comprendidos desde la Teoría del Derecho”. En Derecho E Sociedad, PUCP, No 42, pp. 129-135.

QUINTANILLA PONCE, Alfredo (200o): "El waqcha Arguedas y los doctores". En Cyberayllu, revista de difusión de temas de cultura y humanidades, Nov. 2000. Disponible en http://www.andes.missouri.edu/andes/Especiales/AQWaqcha/ AQP_Waqcha1.html [fecha de consulta: diciembre de 2018].

ROQUE MANRÍQUEZ, Mercedes (2017): "Estatus jurídico político de los pueblos indígenas del Perú: perspectivas del modelo de Estado Constitucional de Derecho". En Deusto Journal of Human Rights, Universidad de Deusto, No 9, pp. 103-124.

SÁNCHEZ RUBIO, David (2008): "Pluralismo jurídico y emancipación social”. En BELLOSO MARTÍN, Nuria y De JULIOS-CAMPUZANO, Alfonso. ¿Hacia un paradigma cosmopolita del derecho?: pluralismo jurídico, ciudadanía y resolución de conflictos (Oñati, IISJ, Dykinson), pp. 111-129.

SANTOS, Boaventura de Souza (2005): El milenio huérfano. Ensayos para una nueva cultura politica (, Madrid-Bogotá, Trotta/ILSA).

SIEDER, Rachel (2011). "Pueblos indígenas y derecho(s) en América Latina”. En RODRÍGUEZ GARAVITO, César (coord.), El derecho en América Latina: un mapa para el pensamiento jurídico del siglo xxi (Buenos Aires, Siglo Veintiuno Editores).

TAMAYO, José (1980): Historia del indigenismo cusqueño. Siglos xvi-xx (Lima, Instituto Nacional de Cultura).

VALER BELLOTA, Pavel H. (2008): "El regreso de las culturas en América Latina. El nuevo espacio de la cultura, desafío indígena a los partidos y movimientos democráticos (del Perú)". En Reflexión Política, Universidad Autónoma de Bucaramanga, vol. 10, No 19, pp. 96-105. 
VALER BELLOTA, Pavel. (2011) "Movimiento social e indigenismo político aymara. Descentralización y proyecto de Estado multinacional". En Revista Argumentos, Instituto de Estudios Peruanos, año 5, $\mathrm{N}^{\circ}$ 5. Disponible en https:// revistaargumentos.iep.org.pe/wp-content/uploads/2014/o7/valer.pdf [ fecha de consulta: diciembre de 2018].

VALER BELLOTA, Pável H. (2016): "El neoconstitucionalismo multicultural en América Latina”. En Revista de la Facultad de Derecho y Ciencias Políticas: Derecho y Politica en Sociedades Multiculturales. UNSAAC, No 9, pp. 243-254.

VARGAS LLOSA, Mario (2015): La utopía arcaica. José María Arguedas y las ficciones del indigenismo (Barcelona, Edit. de Bolsillo).

WACKS, Raymond (2014): Philosophy of law: a very short introduction (Oxford, Oxford University Press).

YRIGOYEN FAJARDO, Raquel Z. (2011): "El horizonte del constitucionalismo pluralista: del multiculturalismo a la descolonización”. En RoDRÍGuez GARAVITo, César (coord.), El derecho en América Latina: un mapa para el pensamiento jurídico del siglo XXI (Buenos Aires, Siglo Veintiuno Editores), pp. 109-138. 